\title{
Treprostinil inhibits the recruitment of bone marrow-derived circulating fibrocytes in chronic hypoxic pulmonary hypertension
}

\author{
V.S. Nikam*, R.T. Schermuly*,\# , R. Dumitrascu\#, N. Weissmann\#, G. Kwapiszewska\#, \\ N. Morrell ${ }^{\star}$, W. Klepetko ${ }^{+}$, L. Fink ${ }^{\S}$, W. Seeger*,\# and R. Voswinckel*,\#
}

ABSTRACT: A unique subpopulation of peripheral blood mononuclear cells that exhibit a parallel expression of haematopoietic and mesenchymal markers has been described as "circulating fibrocytes". These cells were demonstrated to obtain a fibroblastic phenotype in tissues or cell culture and contribute to pulmonary fibrotic disorders and tissue remodelling processes.

The aim of our study was to characterise the recruitment of circulating fibrocytes in vivo in the model of chronic hypoxic pulmonary hypertension in mice and to analyse the therapeutic effect of the stable prostacyclin analogue trepostinil with respect to this cell population.

To track circulating fibrocytes in vivo, we transplanted wild-type mice with bone marrow from ubiquitously eGFP expressing mice and subjected them to chronic hypoxia. We observed significantly increased recruitment of circulating fibrocytes to the remodelled pulmonary resistance arteries in response to hypoxia. Treatment with treprostinil significantly reduced the recruitment of these cells compared to normoxic mice. Treprostinil also reduced right ventricular systolic pressure and slightly reduced the vascular remodelling but failed to reverse the right ventricular hypertrophy.

In summary, we show that circulating fibrocytes contribute to hypoxic pulmonary vascular remodelling and may be specifically targeted by a prostacyclin analogue. Further investigations of cellular and paracrine mechanisms are warranted to decipher their role in pulmonary hypertension.

KEYWORDS: Circulating fibrocytes, prostacyclin, pulmonary hypertension, pulmonary vascular disease

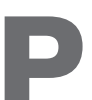

ulmonary hypertension is a chronic and potentially fatal disease resulting from various causes [1]. Lung diseases such as chronic obstructive or interstitial pulmonary disease may lead to chronic intrapulmonary hypoxia and subsequent pulmonary hypertension. It is characterised by increased pulmonary vascular resistance, elevation of pulmonary artery pressure, subsequent right ventricular dysfunction and ventricular hypertrophy. The prominent histological features are hypertrophy and hyperplasia of all vascular layers of the arteries and arterioles leading to vascular obliteration $[2,3]$. Vascular remodelling in pulmonary hypertension is thought to be orchestrated by an interplay between various cell types (adventitial fibroblast, smooth muscle cells, endothelial cells or progenitor cells) either of resident origin or extra pulmonary origin, and their homing, differentiation and release of various mediators [4, 5]. Prostacyclin and its stable analogues iloprost and treprostinil are approved therapies for pulmonary arterial hypertension (PAH) patients $[1,6]$. They act predominantly as vasodilators but also display antiproliferative, anti-inflammatory and antiaggregatory effects $[7,8]$.

Bone marrow-derived cells have been shown to participate in angiogenesis, vascular repair and tissue remodelling of various organs [9-11]. The circulating progenitor cells were demonstrated to assume a mesenchymal or fibroblastic phenotype at the site of tissue injury in animal models of pathological conditions. In this regard, recent reports suggested that a subpopulation of leukocytes contributes to various fibroproliferative

\section{AFFILIATIONS}

*Dept of Lung Development and Remodelling, Max-Planck-Institute for Heart and Lung Research, Bad Nauheim, and

Depts of ${ }^{\#}$ Internal Medicine, and

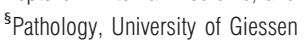
Lung Centre, University Hospital Giessen and Marburg, Giessen, Germany.

-University of Cambridge, School of Clinical Medicine, Addenbrookes

Hospital, Cambridge, UK.

+Dept of Transplant Surgery,

Allgemeines Krankenhaus der Stadt

Wien (AKH), Vienna, Austria.

CORRESPONDENCE

R. Voswinckel

Max-Planck-Institute for Heart and

Lung Research

Parkstrasse 1

61231 Bad Nauheim

Germany

E-mail: robert.voswinckel@

mpi-bn.mpg.de

Received:

Feb 172009

Accepted after revision:

May 012010

First published online:

June 042010 
pathologies, such as pulmonary fibrosis, airway remodelling in asthma and organ fibrosis in scleroderma [12-17]. These circulating progenitor cells from peripheral blood $(<1 \%)$, designated "circulating fibrocytes" by BuCALA et al. [18], exhibit a parallel expression of haematopoietic and mesenchymal antigens (CD45+, CD34+, collagen I and III, and vimentin). A study by НАSнIмото et al. [19], using a chimeric mouse model with GFP expressing bone marrow cells, has shown the significant contribution of bone marrow derived $\mathrm{GFP}^{+} /$collagenI ${ }^{+}$fibroblasts to bleomycin induced lung fibrosis. The contribution of circulating fibrocytes to organ fibrosis and extracellular matrix deposition in experimental pulmonary fibrosis was suggested by correlation of $\mathrm{CD}^{+} 5^{+} /$collagenI $^{+} /$ $\mathrm{CXCR}^{+}$circulating fibrocyte recruitment with increased collagen deposition [14]. Massive cellular recruitment, especially to the adventitial layer of pulmonary arteries, was shown in the setting of hypoxia induced pulmonary hypertension in a rat and a calf model of pulmonary hypertension and was linked to increased numbers of fibroblasts in the adventitia [20]. Bone marrow-derived smooth muscle cell recruitment to pulmonary tissues has been reported in chronic hypoxic mice [21].

Despite the growing understanding of the pathobiology of pulmonary hypertension, it is still an open question if, apart from local residing cells, cells from extra-pulmonary origin have a potential impact on the process of vascular remodelling, which are the mechanisms that lead to the recruitment of these cells to the site of injury and how differentiation of recruited cells is regulated and mediates vascular remodelling in the progression of disease. Additionally, the impact of the currently approved therapies for $\mathrm{PAH}$, such as prostacyclin and its analogues, has not been studied with regard to these extra-pulmonary originating cells. Therefore, we aimed to investigate whether these circulating progenitors do contribute to pulmonary vascular remodelling in a murine model of pulmonary hypertension and how prostacyclin analogues modulate circulating fibrocyte adhesion, differentiation, in vivo recruitment and vascular remodelling.

To address this, we first identified and characterised circulating fibrocytes isolated from peripheral blood in cell culture as well as in vivo using a panel of mesenchymal and haematopoietic markers. We further investigated the recruitment of circulating fibrocytes to pulmonary resistance arteries in response to chronic hypoxia in GFP-bone marrow chimeric mice and evaluated the influence of continuous intravenous infusion of the prostanoid analogue treprostinil.

\section{MATERIALS AND METHODS}

\section{Immunohistochemistry on paraffin embedded lung tissue of $\mathrm{PAH}$ patients}

Use of patient material was approved by the local international review board (University of Giessen, Giessen, Germany) and patients' informed consent was obtained before tissue or blood donation. Lungs were fixed overnight in $4 \%$ paraformaldehyde (PFA) at $4{ }^{\circ} \mathrm{C}$, dehydrated over a graded series of alcohol, and paraffin embedded. Sections of $4-10 \mu \mathrm{m}$ were cut on a microtome (Leica, Wetzler, Germany). Antigen retrieval was performed by incubation with trypsin solution (Digest All 2; Zymed, Berlin, Germany) for $10 \mathrm{~min}$ at $37^{\circ} \mathrm{C}$ or microwave heating for $8 \mathrm{~min}$ using $1 \mathrm{mM}$ EDTA. Antibody staining was performed following standard procedures. All incubations and washes were performed with buffer containing 3\% bovine serum albumin (BSA) and $0.2 \%$ Triton X-100 in 1X PBS, pH 7.4. Unspecific binding sites were blocked for 45-60 mins with goat serum and buffer (1:1 volume/volume ratio). The sections were then incubated with primary and secondary antibodies for $60 \mathrm{~min}$ followed by nuclear staining for 5-10 min with TO ${ }_{\mathbb{R}}-\mathrm{PRO}-3$ iodide (Molecular probes, Germany). The sections were examined with a Leica TCS confocal microscope (Leica).

\section{Animals}

C57BL/6N mice were obtained from Charles River Laboratories (Montreal, QC, Canada) and C57BL/6TgN (eGFP) transgenic mice were obtained from Jackson Labs (Bar Harbor, ME, USA) [22]. Animals were housed under controlled temperature and lighting (12/12-h light/dark cycle), and fed with commercial animal feed and water ad libitum. All experiments were performed according to the institutional guidelines that comply with national and international regulations.

\section{Enhanced GFP chimeric mice}

The eGFP chimeric mice were created as described previously [23]. Briefly, C57BL/6N wild type mice, age 8-10 weeks, were lethally irradiated with $11 \mathrm{~Gy}$ from a caesium source and received $2-5 \times 10^{6}$ bone marrow cells from eGFP positive mice by tail vein injection. Bone marrow was harvested by flushing tibias and femurs of transgenic mice which expressed the reporter gene enhanced green fluorescent protein (eGFP) under the control of a chicken $\beta$-actin promoter and cytomegalovirus enhancer. These transgenic mice ubiquitously express green fluorescence and were bred in the identical C57BL/6N background as the cell recipients. Success of bone marrow transplantation was monitored by flow cytometry of peripheral blood (FACSan flow cytometer; Becton Dickinson, Germany). 4 weeks after the transplantation $>80 \%$ of blood cells expressed eGFP.

Mouse model of hypoxia induced pulmonary hypertension Bone marrow transplanted (BMT) mice were divided into five different groups with each group consisting of six to 10 mice. One group of mice was exposed to hypoxia $(10 \%$ inspired oxygen fraction) in a normobaric chamber as described previously [24, 25] whereas the second group (control BMT) of animals were placed in a normoxic chamber with a normal oxygen environment ( $21 \%$ inspired $\mathrm{O}_{2}$ fraction) for 28 days. Sham group mice received saline treatment whereas two other groups of mice received treprostinil infusions of different dose levels $\left(14 \mathrm{ng} \cdot \mathrm{kg}^{-1} \cdot \mathrm{min}^{-1}\right.$ and $\left.70 \mathrm{ng} \cdot \mathrm{kg}^{-1} \cdot \mathrm{min}^{-1}\right)$ and were exposed to hypoxia for 4 weeks. For comparison, human infusion rates in PAH therapy vary from 10 to $60 \mathrm{ng} \cdot \mathrm{kg}^{-1} \cdot \mathrm{min}^{-1}$ [26-29].

\section{Surgical procedure for osmotic minipump implantation in the mice}

Osmotic minipumps (model number 2004; infusion rate $0.25 \mu \mathrm{L} \cdot \mathrm{min}^{-1}$; Alzet, CA, USA) were filled with either treprostinil (Remodulin $\mathbb{\circledR}$; United Therapeutics Corp., Research Triangle, NC, USA) or sterile $0.9 \%$ injectable saline (Braun, Melsungen, Germany) and equilibrated at $37^{\circ} \mathrm{C}$ in PBS for $48 \mathrm{~h}$ before implantation. The mice were anaesthetised with 30 $60 \mathrm{mg} \cdot \mathrm{kg}^{-1}$ ketamine (Pfizer, Berlin, Germany) and $5-10 \mathrm{mg} \cdot \mathrm{kg}^{-1}$ xylazine (Bayer, Leverkusen, Germany), and a $2 \mathrm{~cm}^{2}$ area distal 
to the head on the left ventral and dorsal side were shaved. The minipump was implanted subcutaneously on the back and the cannula connected to the pump was tunnelled subcutaneously to be inserted in the external jugular vein and was kept in position with a silk suture. Incisions were closed with surgical ligatures and animals had access to food and water ad libitum. The animals received post-operative analgesia with buprenorphin injections twice daily for 3 days.

\section{Haemodynamic measurements and ventricular mass}

The animals were anaesthetised by intraperitoneal injection of ketamine and xylazine as described above and placed on a heating pad to maintain the body temperature in the physiological range. The trachea was cannulated and attached to a mouse respirator (SAR830A/P; IITC Life Science, Woodland Hills, CA, USA) with $10 \mathrm{~mL} \cdot \mathrm{kg}^{-1}$ body weight and tidal volume of 100 breaths $\cdot \mathrm{min}^{-1}$. Inspiratory oxygen fraction $\left(\mathrm{FI}, \mathrm{O}_{2}\right)$ was set to 0.5 , and a positive end-expiratory pressure of $1.0 \mathrm{cmH}_{2} \mathrm{O}$ was applied. Systemic blood pressure was recorded from the left carotid artery by a cannula attached to a fluid-filled pressure transducer (Braun, Germany). The right jugular vein was used to measure the right ventricular pressure by inserting a custom made silicon catheter through the jugular vein into the right ventricle. All instruments were calibrated before taking the measurements.

After systemic and right ventricular pressure measurement, the lung and heart were flushed with saline followed by perfusion through the pulmonary artery and instillation of the trachea with 1\% buffered PFA (Sigma-Aldrich, Germany) with pressures of $20 \mathrm{cmH}_{2} \mathrm{O}$ and $10 \mathrm{cmH}_{2} \mathrm{O}$, respectively. Thus, the lung and heart were isolated, the right ventricle (RV) was dissected from the left ventricle plus septum $(\mathrm{LV}+\mathrm{S})$, and these dissected samples were dried and weighed to obtain the right to left ventricle plus septum ratio $(\mathrm{RV} / \mathrm{LV}+\mathrm{S})$.

\section{Immunohistochemistry of paraffin embedded mouse lung tissue}

The mice lungs were harvested as described previously. Antibody staining was performed following standard procedures. Lungs were post-fixed overnight in $1 \%$ PFA at $4{ }^{\circ} \mathrm{C}$, dehydrated over a graded series of alcohol, and paraffin embedded. Sections of $4-10 \mu \mathrm{m}$ were cut on a microtome (Leica). Antigen retrieval was performed by incubation with trypsin solution (Digest All 2; Zymed) for $10 \mathrm{~min}$ at $37^{\circ} \mathrm{C}$ or microwave heating for $8 \mathrm{~min}$ using $1 \mathrm{mM}$ EDTA. All incubations and washes were performed with histobuffer containing $3 \%$ BSA and $0.2 \%$ Triton $\mathrm{X}-100$ in $1 \times \mathrm{PBS}, \mathrm{pH} 7.4$. Unspecific binding sites were blocked over 45-60 min with goat serum and histobuffer $(1: 1 \mathrm{v} / \mathrm{v}$ ratio). The sections were then incubated with primary and secondary antibodies for $60 \mathrm{~min}$ followed by nuclear staining. The sections were examined with a Leica TCS confocal microscope (Leica).

\section{Morphometry of pulmonary artery remodelling}

The degree of muscularisation due to hypoxia induced pulmonary hypertension in BMT mice was assessed by double staining of $3-\mu \mathrm{m}$ lung sections with $\alpha$-smooth muscle actin (clone 1A4; 1:400; Sigma-Aldrich) and von Willebrand factor antibodies (dilution 1:900; Dako, Hamburg, Germany), as previously described [25]. The nuclei were visualised by methyl-green counter stain and the sections evaluated by light microscopy. The degree of muscularisation was measured with morphometric software as described previously [25]. At $40 \times$ magnification, 80-100 small vessels, which were either surrounded by alveolar ducts or alveoli, were counted. The blood vessels were classified as to the degree of muscularisation into non-muscularised, partially muscularised and completely muscularised. The percent of blood vessels in each category was determined by dividing the number of vessels in that category by the total number of blood vessels counted in the same experimental group.

\section{Vessel wall thickness measurement}

To measure the vessel wall thickness, the outer (Ro) and inner (Ri) radius was calculated using volume densities of the vessel lumen and the vessel wall using the stereological point counting grids based on the Cavalieri principle in the newCAST software (Visiopharm, Hoersholm, Denmark). The point counting grid was used for volume density analysis. The relative wall thickness of each artery (VWT) was calculated by the formula: VWT $=($ Ro-Ri) $/$ Ro [30]. Three sections of each mouse lung from five to six animals per group were analysed.

\section{Quantitative PCR for chemokine expression from formalin fixed paraffin embedded mouse lung tissue}

For total RNA isolation, four $10-\mu \mathrm{m}$ thick sections were cut from a formalin fixed paraffin embedded (FFPE) tissue block. The RecoverAll ${ }^{\mathrm{TM}}$ Total Nucleic Acid Isolation Optimized for FFPE Samples (Ambion Inc., Austin, TX, USA) was used for the RNA isolation. The RNA was isolated as per manufacturer's instruction. Briefly, the protocol followed the following steps: deparaffinisation with $100 \%$ xylene followed by washing with $100 \%$ ethanol. Following this, the tissue was digested with proteinase K and RNA was isolated. The isolated RNA was incubated with DNase and finally purified. For reverse transcription (RT) analysis, extracted RNA (500 ng) was converted to cDNA using the following components: $2 \mu \mathrm{L}$ of $10 \times$ RT buffer II, $4 \mu \mathrm{L}$ of $\mathrm{MgCl}_{2}(25 \mathrm{mM}), 2 \mu \mathrm{L}$ of deoxynucleotide mixture $(5 \mathrm{mM}), 0.5 \mu \mathrm{L}$ of Rnase inhibitor, $1 \mu \mathrm{L}$ of random hexamer and $1 \mu \mathrm{L}$ of Maloney murine leukemia virus (all components were obtained from Applied Biosystems, Foster City, CA, USA). The volume of the mixture made up to $20 \mu \mathrm{L}$. The mixture was then incubated at $43^{\circ} \mathrm{C}$ for $75 \mathrm{~min}$ followed by inactivation of reverse transcriptase at $95^{\circ} \mathrm{C}$.

Quantitative PCR was performed by the CFX96 ${ }^{\mathrm{TM}}$ C1000Thermal cycler (BioRad, Hercules, CA, USA). 18S ribosomal RNA, a ubiquitously as well as consistently expressed gene, was used as reference. The reactions (final volume: $25 \mu \mathrm{L}$ ) were set up with the SYBR ${ }^{\mathrm{TM}}$ Green PCR Core Reagents (Applied Biosystems) according to the manufacturer's protocol using $2 \mu \mathrm{L}$ of cDNA. Cycling conditions were $95^{\circ} \mathrm{C}$ for $6 \mathrm{~min}$, followed by 45 cycles of $95^{\circ} \mathrm{C}$ for $20 \mathrm{~s}, 59^{\circ} \mathrm{C}$ for $30 \mathrm{~s}$ and $73^{\circ} \mathrm{C}$ for $30 \mathrm{~s}$. Due to the nonselective dsDNA binding of the $\mathrm{SYBR}^{\mathrm{TM}}$ Green I dye, melting curve analysis and gel electrophoresis were performed to confirm the exclusive amplification of the expected PCR product. The primers used for the real time PCR are listed in table 1. 
TABLE 1 Primers for quantitative PCR

\begin{tabular}{llll} 
Gene & Forward primer & Reverse primer & Amplicon size bp \\
\hline CXCR4 & 5'GCTTCCGGGATGAAACGTC3' & 5'ACCAATCCATTGCCGACTATG3' & 94 \\
CCR7 & 5'CCATGACGGATACCTACCTGC3' & 5'GATCCAGGACTTGGCTTCGCT3' & 98 \\
\hline
\end{tabular}

\section{Statistical analysis}

The results are expressed as mean \pm SEM, unless otherwise stated. The data were analysed by ANOVA with Bonferroni's multiple comparison post hoc test using GraphPad Prism statistical software (GraphPad Software, La Jolla, CA, USA). A p-value $<0.05$ was considered to be significant. Error bars depict SEM.
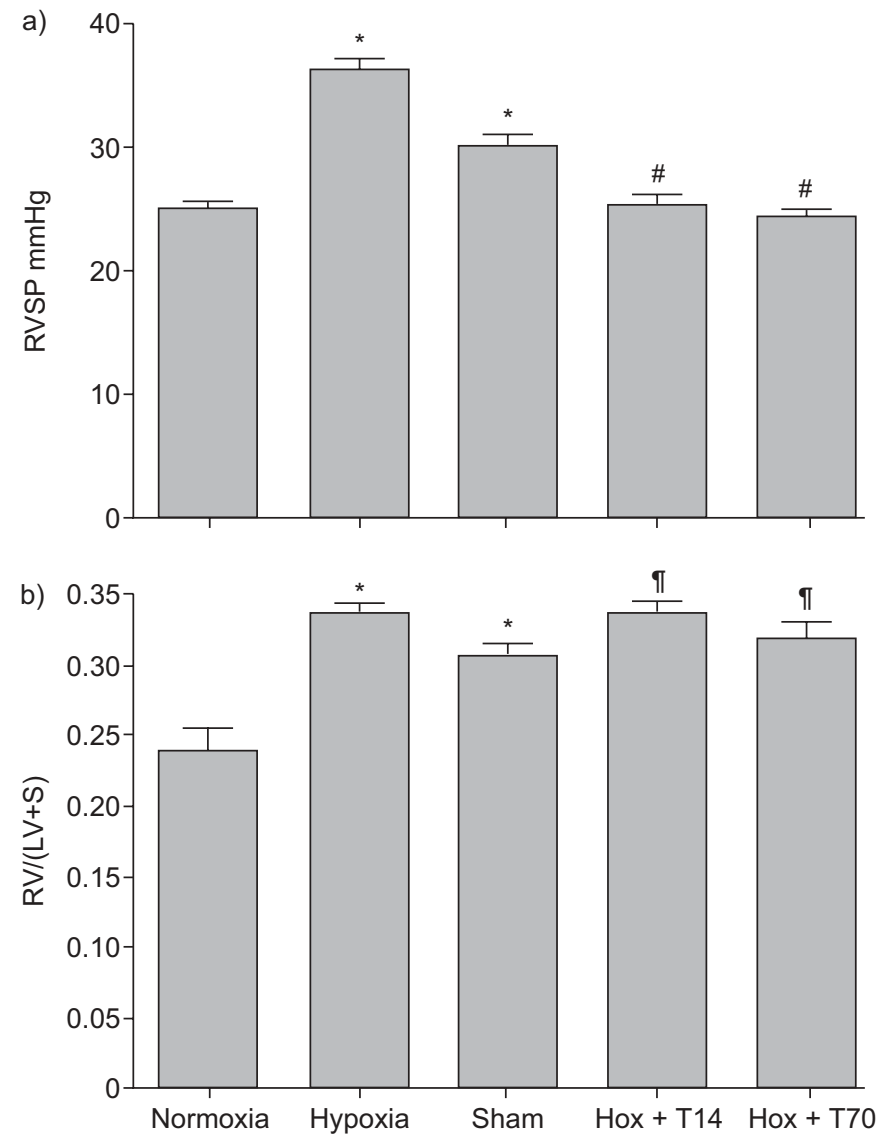

FIGURE 1. Haemodynamic and right ventricular hypertrophy. a) The right ventricular systolic pressure (RVSP) of mice exposed to hypoxia (4 week) and hypoxia (4 week)+saline (sham) was increased significantly compared to the mice kept under normoxic conditions. The mice kept under hypoxia and treated with 14 or $70 \mathrm{ng} \cdot \mathrm{kg}^{-1} \cdot \mathrm{min}^{-1}$ treprostinil (Hox $+\mathrm{T} 14$ and Hox $+\mathrm{T} 70$, respectively) showed normalisation of right ventricular pressure. b) The ratio of right ventricle to left ventricle with septum $(\mathrm{RV} /(\mathrm{LV}+\mathrm{S}))$ showed a significant increase in hypoxic and sham group animals compared to normoxic mice. The ratio was not significantly altered by the treprostinil treatment at both dose levels. The statistical analysis was performed using ANOVA with Bonferroni's multiple comparison post hoc test $(n=6)$. *: $p<0.05$ considered to be significant versus normoxia; ${ }^{*}: p<0.05$ significant versus sham and hypoxia; " $\mathrm{p}>0.05$ nonsignificant versus sham.

\section{RESULTS}

Hypoxia-induced pulmonary hypertension in eGFP bone marrow chimeric mice and treprostinil infusion improved haemodynamic

The success of bone marrow transplantation was assessed by flow cytometry of peripheral blood cells after 4 weeks of reconstitution. At that time, already $80-90 \%$ of the peripheral blood cells expressed GFP.

The GFP chimeric mice kept in hypoxia alone, in hypoxia with continuous saline or treprostinil infusion, or in normoxia were analysed for haemodynamic parameters as described in the Materials and methods section [24, 25]. The hypoxic mice showed a remarkable increase in right ventricular systolic pressure $(36.57 \pm 0.705 \mathrm{mmHg})$ compared to mice kept in normoxic chambers $(25.2 \pm 0.43 \mathrm{mmHg})$, as shown in figure 1a and table 2 .

The sham mice received continuous saline infusion through subcutaneously implanted minipumps via the jugular vein in the same way as treprostinil infused animals and were kept under hypoxia. The sham mice showed an increase in right ventricular systolic pressure $(30.3 \pm 0.8 \mathrm{mmHg})$ compared to normoxic control animals without implanted pumps. A both does levels (14 and $70 \mathrm{ng} \cdot \mathrm{kg}^{-1} \cdot \mathrm{min}^{-1}$ ) the treprostinil infusion animals showed a significant decrease in right ventricular systolic pressure compared to the hypoxic and sham animals (fig. $1 \mathrm{a}$ and table 2).

\section{Right ventricular hypertrophy could not be reversed with treprostinil treatment in hypoxia-induced pulmonary hypertension animals}

Right ventricular hypertrophy was assessed by the dry weight ratio of $R V$ to $L V+S$. The ratio of $R V /(L V+S)$ exhibited significant hypertrophy of the right ventricle in the hypoxic chimeric mice in comparison to normoxic chimeric mice (fig. $1 \mathrm{~b}$ and table 2). Sham group animals showed a significant increase in right ventricular hypertrophy compared to

\begin{tabular}{lcccc} 
TABLE 2 & \multicolumn{5}{l}{$\begin{array}{l}\text { Haemodynamic parameters with treprostinil } \\
\text { treatment in bone marrow transplanted mice }\end{array}$} \\
Groups & RVSP $\mathbf{~ m m H g}$ & SAP $\mathbf{~ m m H g}$ & Haematocrit \% & $\mathbf{R V / ( L V + S )}$ \\
\hline Normoxia & $25.2 \pm 0.43$ & $76 \pm 5.1$ & $45.8 \pm 0.37$ & $0.24 \pm 0.014$ \\
Hypoxia & $36.6 \pm 0.7$ & $76.6 \pm 2.9$ & $63.0 \pm 1.3$ & $0.34 \pm 0.01$ \\
Sham & $30.29 \pm 0.8$ & $59.1 \pm 3.1$ & $53.2 \pm 1.2$ & $0.31 \pm 0.02$ \\
Hox + T14 & $25.75 \pm 0.5$ & $62.2 \pm 3.9$ & $55.0 \pm 1.1$ & $0.34 \pm 0.02$ \\
Hox + T70 & $24.75 \pm 0.22$ & $57.8 \pm 2.4$ & $62.4 \pm 1.03$ & $0.32 \pm 0.01$ \\
\hline
\end{tabular}

RVSP: right ventricular systolic pressure; SAP: systemic arterial pressure; RV $(L V+S)$ : ratio of right ventricle to left ventricle with septum. 


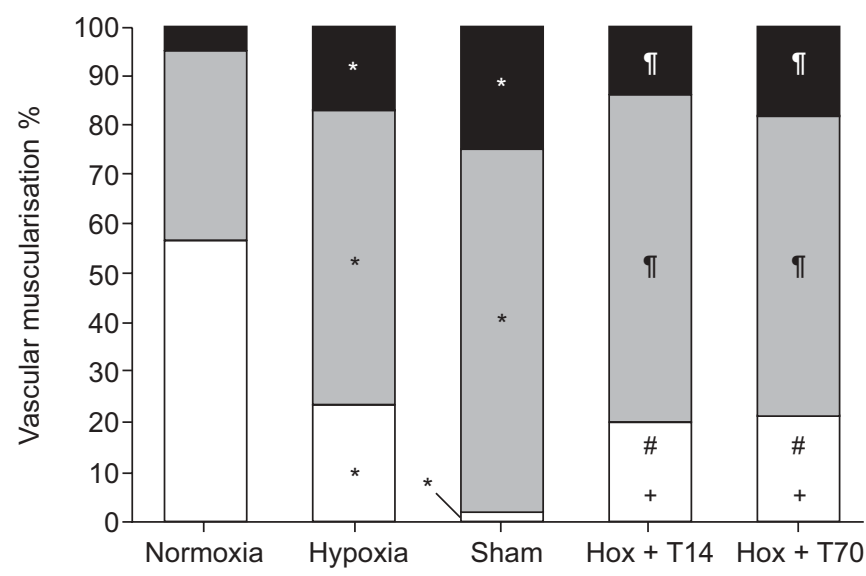

FIGURE 2. Vascular remodelling $(20-70 \mu \mathrm{m}$ vessel diameter) was partially reversed with treprostinil treatment. The percentage of vascular muscularisation categorised as non-muscularised $(\square)$, partially muscularised $(\square)$ and completely muscularised ( $\mathbf{a})$ exhibited significant increase of muscularisation of pulmonary resistance arteries during chronic hypoxia in hypoxic and sham mice. The treprostinil treatment partially reversed the muscularisation with an increase in non-muscualrised blood vessels. ANOVA with Bonferroni's multiple comparison test was performed for statistical analysis $(n=6)$. Hox $+T 14$ : hypoxia and treated with $14 \mathrm{ng} \cdot \mathrm{kg}^{-1} \cdot \mathrm{min}^{-1}$ treprostinil; Hox + T70: hypoxia and treated with $70 \mathrm{ng} \cdot \mathrm{kg}^{-1} \cdot \mathrm{min}^{-1}$ treprostinil. *: $\mathrm{p}<0.05$ considered to be significant versus normoxic group; ${ }^{*}: p<0.05$ significant compared to sham group mice; " $p>0.05$ nonsignificant versus sham group; ${ }^{+}: p>0.05$ nonsignificant versus hypoxia group mice without minipump implantation.

normoxic animals. However, the treprostinil treatment failed to reverse the ratio significantly, as shown in figure $1 \mathrm{~b}$ and table 2 . The haematocrit values and haemodynamic measurements from mice kept under hypoxia and normoxia conditions and those receiving treatment are summarised in table 2.

\section{Treprostinil infusion slightly reduced the vascular remodelling in response to chronic hypoxia exposure}

Chronic hypoxia-induced remodelling of pulmonary resistance arteries was analysed in immunohistological sections by double staining with $\alpha$-smooth muscle actin and von Willebrand factor. The degree of muscularisation was assessed quantitatively as described in the Materials and methods section [24, 25]. The normoxic control mice mainly exhibited non-muscularised and partially muscularised blood vessels of 20-70 $\mu \mathrm{M}$ diameters and $<10 \%$ fully muscularised blood vessels.

Chronic hypoxia induced a dramatic increase in muscularisation in GFP-BMT mice with concomitant decrease of nonmuscularised vessels and increase of partially and fully muscularised blood vessel as shown in figure 2. The pathophysiological and histological features of hypoxia-induced pulmonary hypertension in GFP-BMT mice were similar to the non-irradiated, non-BMT wild-type mice subjected to similar conditions, as reported previously [24, 25].

The vascular remodelling was slightly prevented by treprostinil at two different infusion rates in vivo, as shown by a reduction of muscularisation with an increase in non-muscularised blood vessels compared to the sham infused group, but not significantly reduced compared to hypoxic animals without minipump implantation (fig. 2).

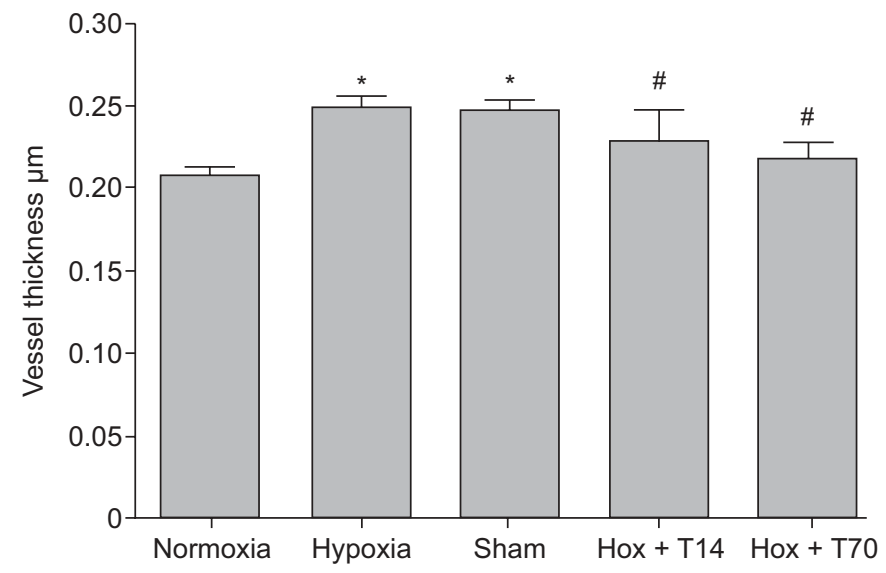

FIGURE 3. Effect of treprostinil treatment on vessel wall thickness. The vessel wall thickness was found to be increased with chronic exposure to hypoxia in hypoxic and sham animals. The treprostinil treatment at both dose levels slightly reduced the vessel wall thickness compared to sham and hypoxic mice but was statistically nonsignificant. ANOVA with Bonferroni's multiple comparison post hoc test was performed $(\mathrm{n}=6)$. Hox $+\mathrm{T14}$ : hypoxia and treated with $14 \mathrm{ng} \cdot \mathrm{kg}^{-1} \cdot \mathrm{min}^{-1}$ treprostinil; Hox + T70: hypoxia and treated with $70 \mathrm{ng} \cdot \mathrm{kg}^{-1} \cdot \mathrm{min}^{-1}$ treprostinil. *: $p<0.05$ considered to be significant versus the normoxic group; *: $p>0.05$ nonsignificant versus sham group as well as hypoxic mice without minipump implantation.

The vessel wall thickness was significantly increased by hypoxia. The treprostinil treatment slightly reduced the vessel wall thickness compared to sham and hypoxic animals but it was not statistically significant (fig. 3).

\section{In vivo characterisation and identification of circulating fibrocytes}

Lung tissue sections were prepared from 10 idiopathic PAH patient lungs. Immunohistological analysis for collagen 1 and CD45 double-positive cells showed the regular, but rare, presence of circulating fibrocytes in pulmonary resistance arteries, as shown in the figure $4 \mathrm{a}-\mathrm{e}$ and table 3 . Two patients had higher numbers of fibrocytes in comparison to the rest of the patients (table 3 ). The number of collagen 1 positive cells was higher, but their origin (resident or recruited) is unclear as there are reports suggesting the loss of haematopoietic markers during differentiations of the fibrocytes [14, 15, 31].

Bone marrow derived GFP+ cells significantly accumulated in the perivascular area and arterial wall of pulmonary arteries in response to hypoxia. The characterisation of circulating GFP+ cells recruited to the perivascular area of pulmonary vessels revealed the co-expression of CD45 and collagen 1 as well as vimentin, as shown in the figure 5. A few host derived GFP negative/CD45 positive cells could also be found in the perivascular area and represented cells which had been recruited before bone marrow exchange.

\section{Recruitment profile of circulating fibrocytes to the pulmonary arterial wall during development of chronic hypoxic pulmonary hypertension}

We quantified the recruitment of bone marrow derived GFP+, collagen 1+/GFP+, collagen 1-/GFP+, CD45+/GFP+ and CD45-/ GFP+ cells to the pulmonary arteries by counting the cells of 

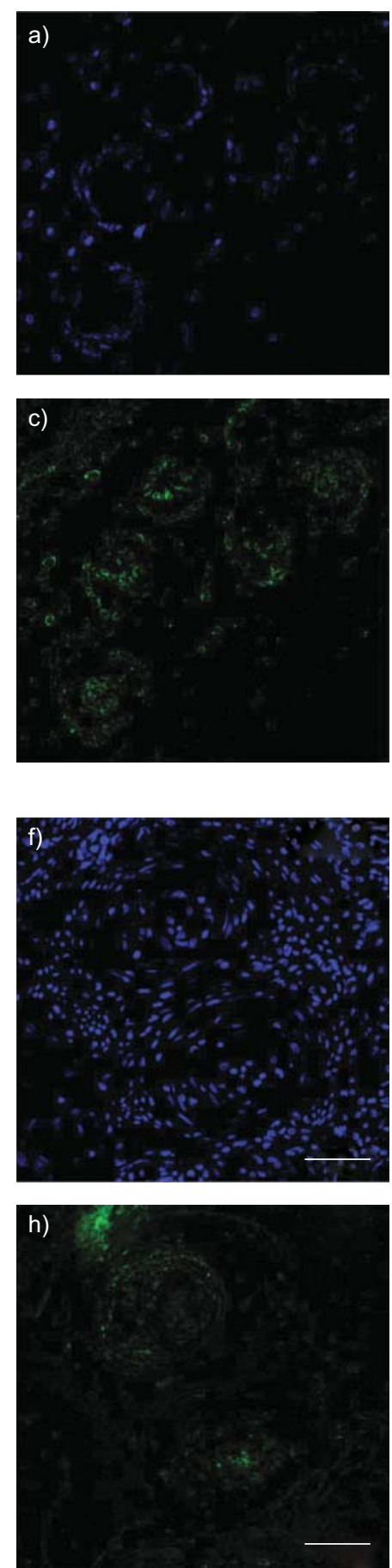

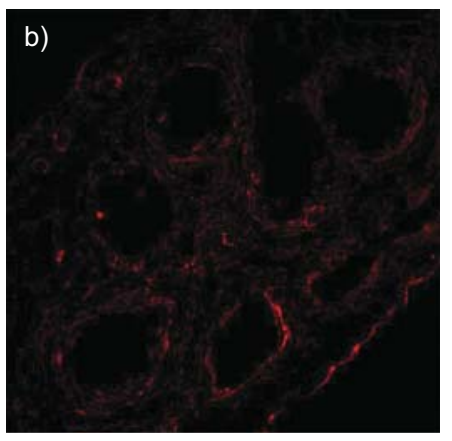

d)
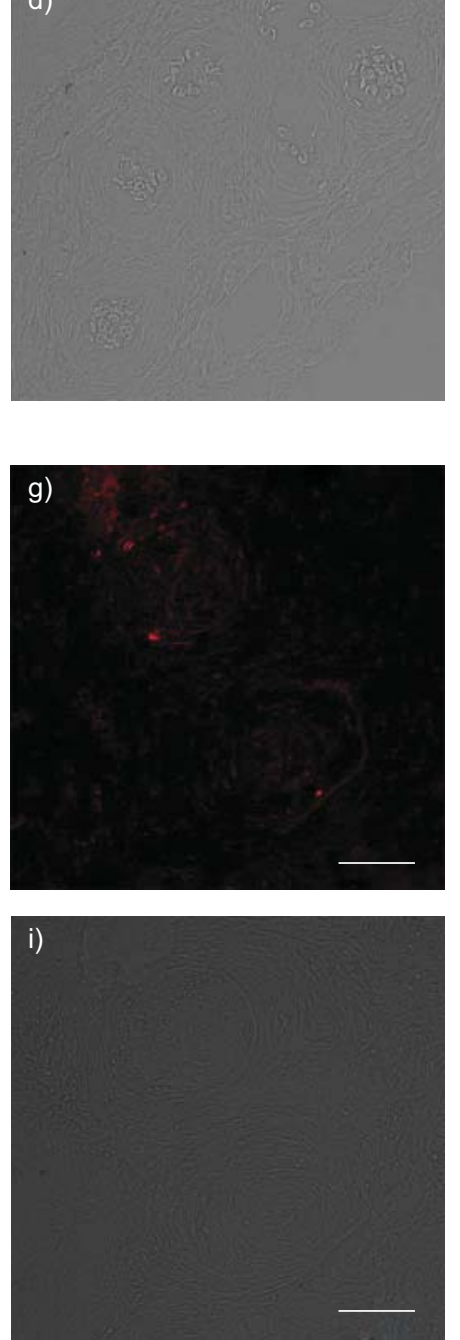
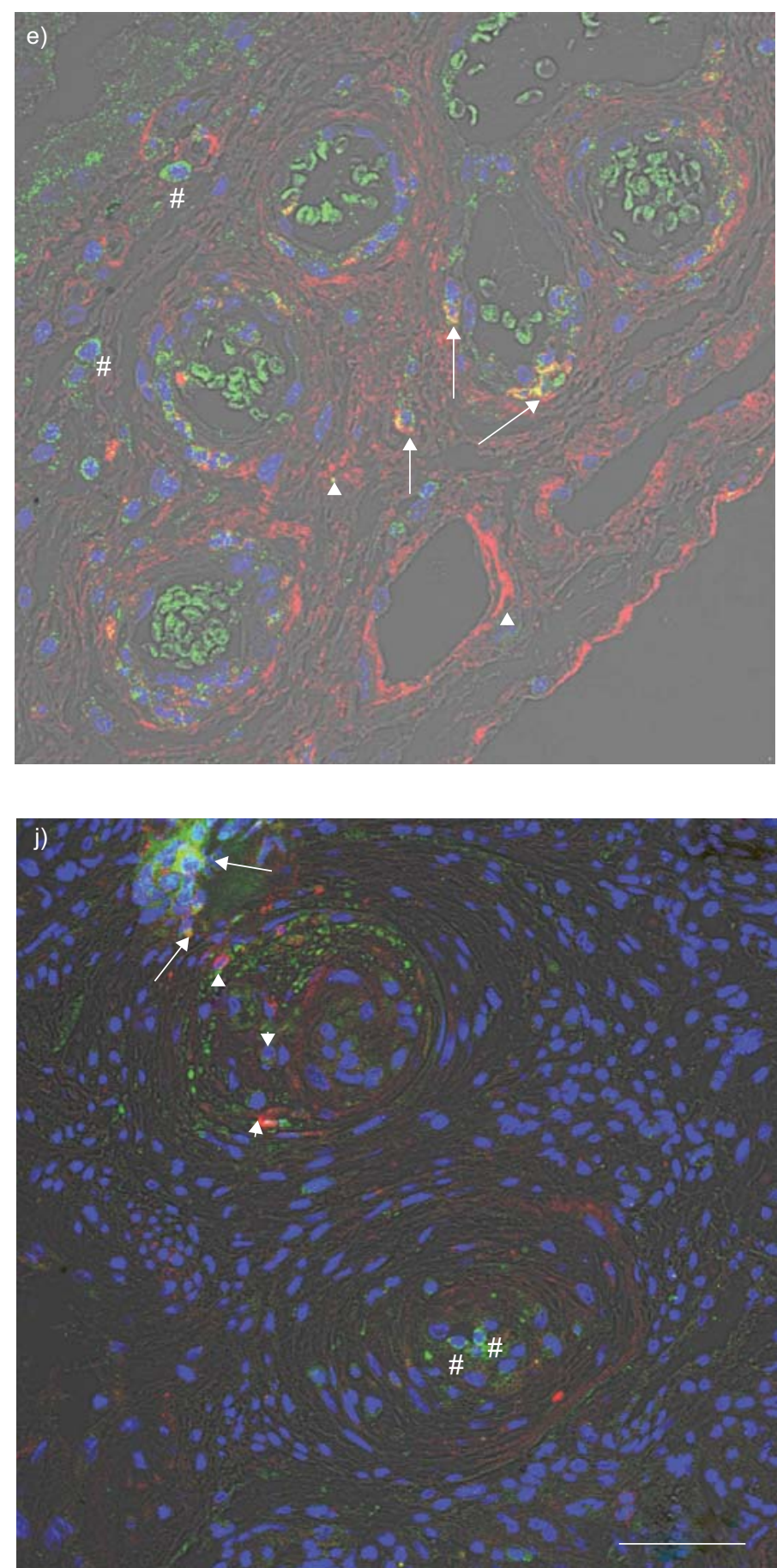

FIGURE 4. Characterisation of circulating fibrocytes in the pulmonary arteries of idiopathic pulmonary arterial hypertension patients. The lung tissue was analysed for the presence of circulating fibrocytes using collagen 1 and CD45 markers along with transmitted light differential interference contrast (DIC) images to illustrate tissue organisation and architecture. a-e) Circulating fibrocytes were observed in plexiform lesions (arrows). Collagen 1+ cells (fibroblasts; arrowheads), collagen depositions (arrowheads) and CD45+ cells (leukocytes; \#) were also detected in the tissue. f-j) Pulmonary artery with a concentric lesion showing several fibrocytes in the perivascular area (arrows). a, f) Nuclei, b, g) collagen 1, c, h) CD45, d, i) DIC, and e, j) merge. Scale bar $=50 \mu \mathrm{m}$.

15-20 resistance vessels from random sections from five different sections of each mouse lung and six animals were taken from each group for quantification.

The collagen 1+/GFP+, collagen 1-/GFP+, CD45+/GFP+, $\mathrm{CD} 45-/ \mathrm{GFP}+$ and GFP+ cells significantly accumulated in the pulmonary resistance arteries in response to chronic hypoxia in comparison to normoxic animals. Continuous treprostinil infusion at a rate of $70 \mathrm{ng} \cdot \mathrm{kg}^{-1} \cdot \mathrm{min}^{-1}$ significantly inhibited the recruitment of collagen $1+/ \mathrm{GFP}+$ circulating fibroblasts to the pulmonary arterial wall compared to the sham infusion group. The recruitment of CD45+/GFP+ was 


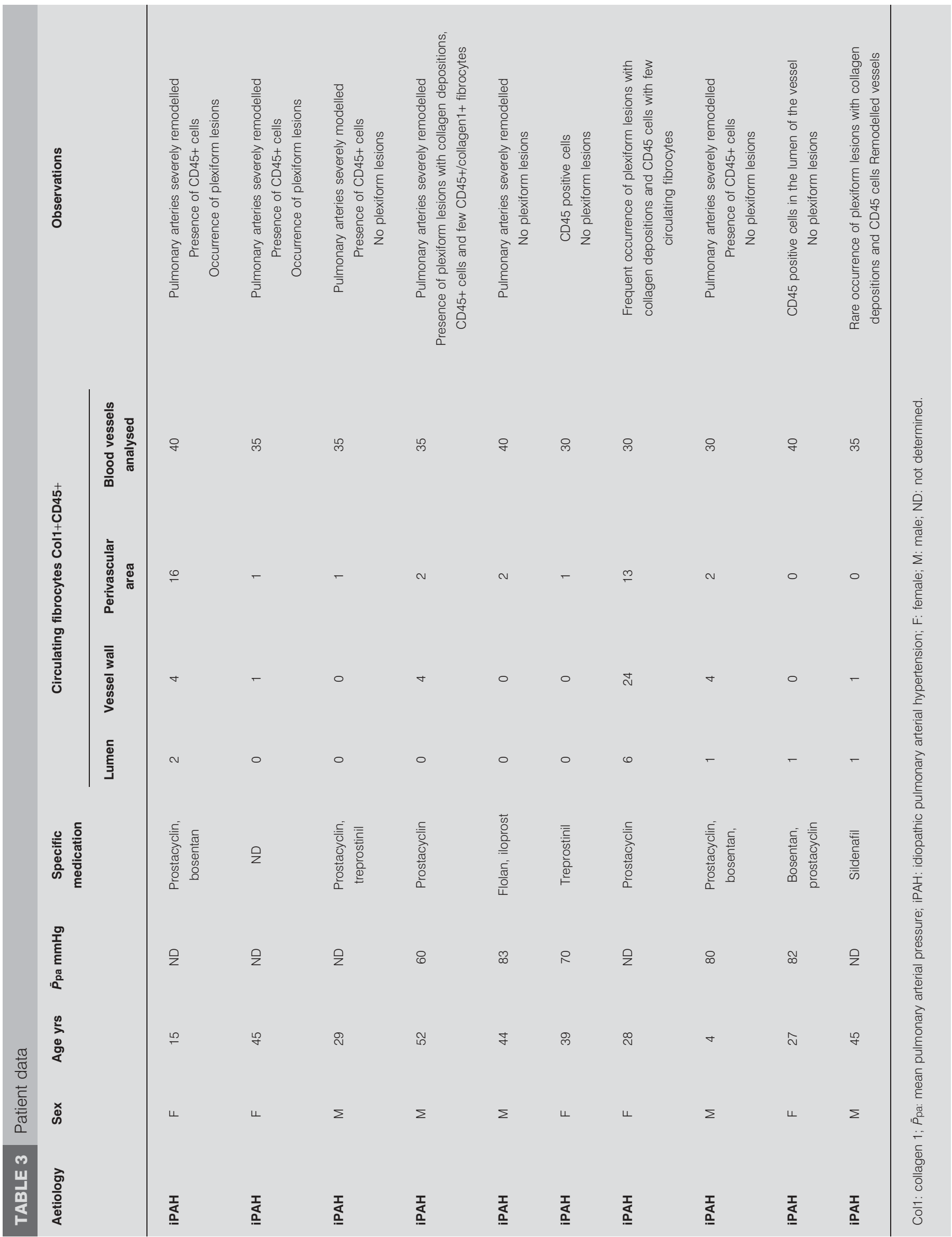



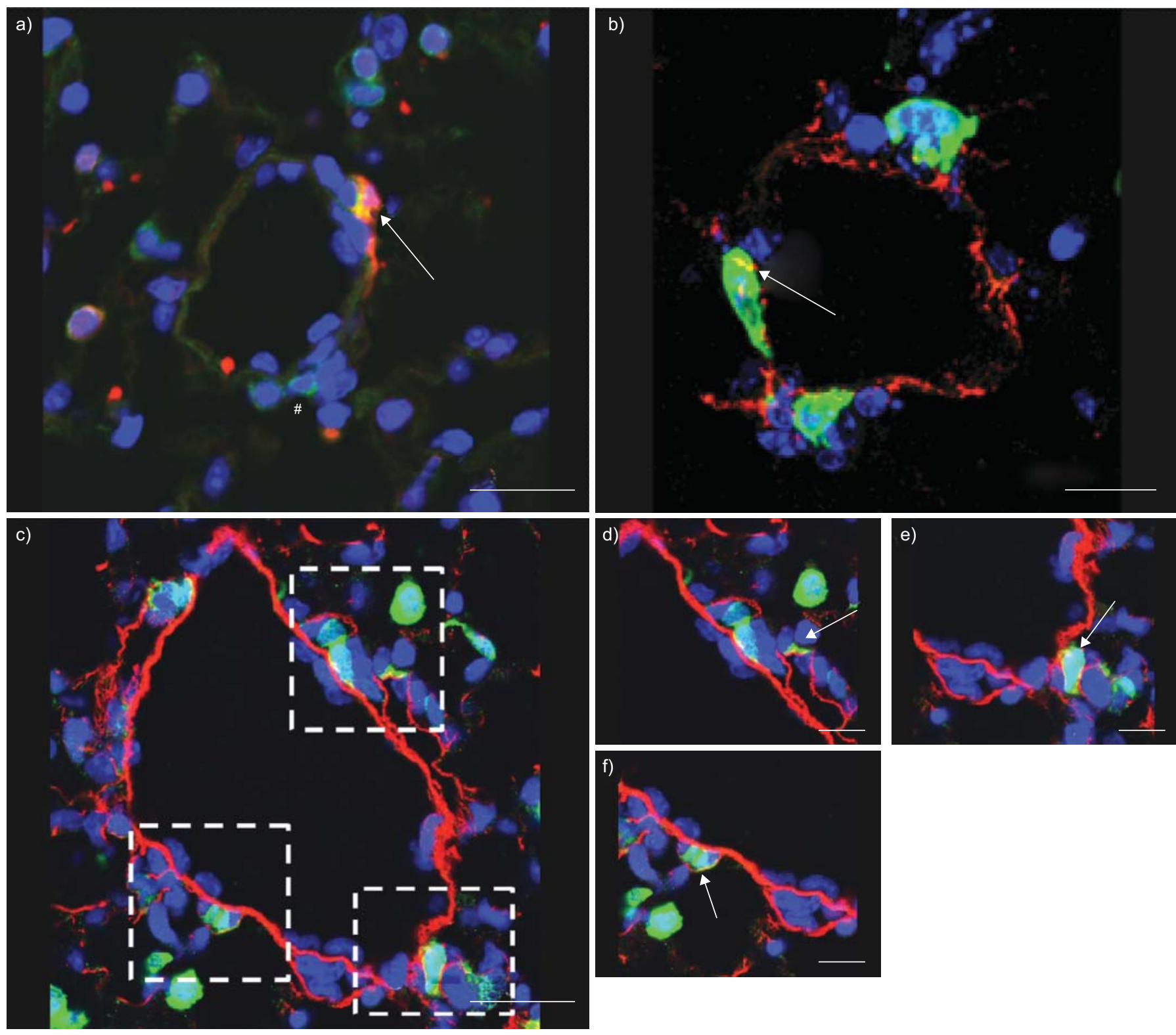

FIGURE 5. In vivo characterisation of circulating fibrocytes in pulmonary arteries of pulmonary hypertensive mice. a) Murine small pulmonary arteries displayed coexpression of haematopoietic (CD45) and bone marrow derived markers (GFP) in the pulmonary arterial wall (arrow). Host derived CD45+ cells (green; \#) were observed in the arterial wall. Scale bar $=21.47 \mu \mathrm{m}$. b) The co-expression of collagen1 (mesenchymal marker) and GFP in circulating fibrocytes (arrows). Scale bar=16.08 $\mu \mathrm{m}$. $\mathrm{c}-\mathrm{f}$ ) Coexpression of vimentin (mesenchymal marker) and GFP by circulating fibrocytes recruited in the pulmonary vascular wall at c) 01:00 h, 05:00 h and 07:00 h (dotted square insets). $d-f$ ) The magnified insets of (c) at 01:00 h, 05:00 h and 07:00 h, respectively. Arrows represent GFP+ vimentin+. c) Scale bar=30 $\mu \mathrm{m}, \mathrm{d}-\mathrm{f}$ ) $\mathrm{scale}$ bars $=15 \mu \mathrm{m}$.

significantly reduced with treprostinil treatment at both dose levels (fig. 6).

\section{Chemokine expression in the lung of the mice subjected to chronic hypoxia and treprostinil treatment by quantitative PCR}

Circulating fibrocytes are known to express various chemokine receptors, such as CXCR4, CCR2 and CCR7 [12, 14, 32]. The mRNA expression levels showed up-regulation of CXCR4 and CCR7 in mice exposed to hypoxia (hypoxia and sham group animals) compared to normoxic mice, as shown in figure 7. The continuous infusion of treprostinil at the dose level of $14 \mathrm{ng} \cdot \mathrm{kg}^{-1} \cdot \mathrm{min}^{-1}$ did not show the downregulation of the chemokine expression compared to sham group mice. However, there is significant downregulation of the CXCR4 and CCR7 expression at a dose of $70 \mathrm{ng} \cdot \mathrm{kg}^{-1} \cdot \mathrm{min}^{-1}$ treprostinil compared to sham group mice, as shown in figure 7 .

\section{DISCUSSION}

Experimental pulmonary hypertension in the setting of hypoxia in mice has been shown to elevate pulmonary arterial pressure due to vascular remodelling [24, 25]. Prominent features of all types of pulmonary hypertension are intimal and medial hypertrophy leading to vasoconstriction. The contribution of diverse type of cells (endothelial cells, smooth muscle cells, fibroblasts, etc.) and their mediators has been proposed in the 

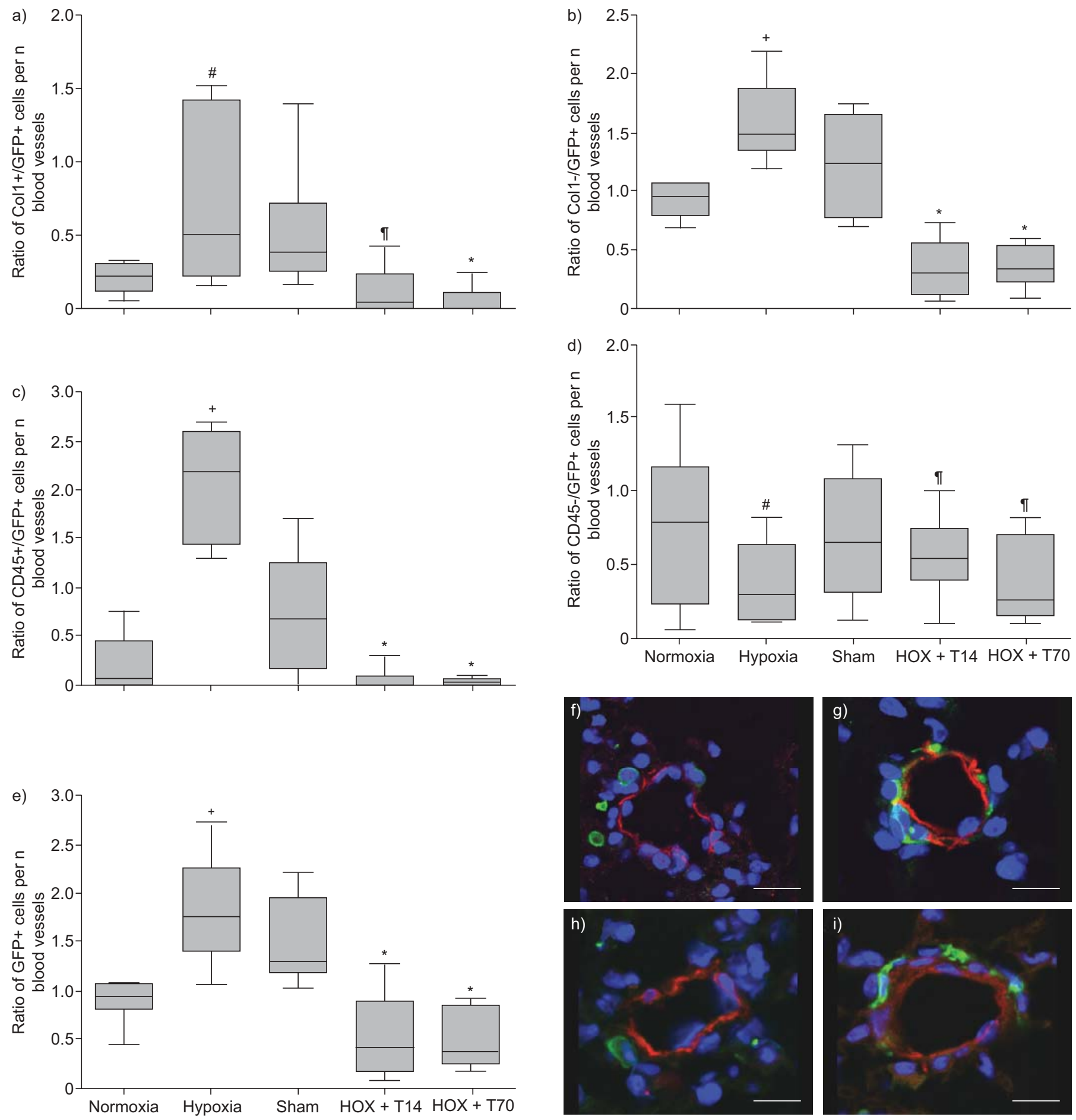

FIGURE 6. In vivo recruitment of circulating fibrocytes to the perivascular area in response to hypoxia is inhibited by treprostinil infusion. a) The number of recruited collagen (Col)1+/GFP+ cells increased in response to chronic hypoxia compared to normoxic mice. The treprostinil treatment at $70 \mathrm{ng} \cdot \mathrm{kg}^{-1} \cdot \mathrm{min}^{-1}$ significantly reduced the Col1+/GFP+ cells. b) Col1-/GFP+ cells significantly accumulated in perivascular area in chronic hypoxia compared to normoxia, and treprostinil treatment remarkably inhibited their accumulation. c) CD45+/GFP+ cells were accumulated in the perivascular area and their recruitment was inhibited with treprostinil infusion at both dose levels. d) The number of CD45-/GFP+ T-cells were not significantly inhibited with treprostinil treatment. e) The number of recruited GFP+ cells significantly ( $p<0.05)$ increased in response to chronic hypoxia compared to normoxic mice. The treatment with treprostinil infusion significantly inhibited the recruitment of circulating fibrocytes. Hox $+\mathrm{T} 14$ : hypoxia and treated with $14 \mathrm{ng} \cdot \mathrm{kg}^{-1} \cdot \mathrm{min}^{-1}$ treprostinil; Hox $+\mathrm{T} 70$ : hypoxia and treated with $70 \mathrm{ng} \cdot \mathrm{kg}^{-1} \cdot \mathrm{min}^{-1}$ treprostinil. ${ }^{*}: \mathrm{p}<0.05$ significant versus sham; ${ }^{*}: \mathrm{p}>0.05 \mathrm{nonsignificant} \mathrm{versus}$ normoxia; ${ }^{\top}: p>0.05$ nonsignificant versus sham ; ${ }^{+}: p<0.05$ significant versus normoxia. f-i) Lung tissue stained for $\alpha$-smooth muscle actin and GFP detected no coexpressing cells in the vascular smooth muscle layer in response to chronic hypoxia in GFP chimeric mice. f) Normoxia, g) hypoxia, h) hypoxia and treated with $14 \mathrm{ng} \cdot \mathrm{kg}^{-1} \cdot \mathrm{min}^{-1}$ treprostinil and i) sham. Scale bars $=20 \mu \mathrm{m}$. ANOVA with Bonferroni's multiple comparison post hoc test was performed $(\mathrm{n}=6)$. 


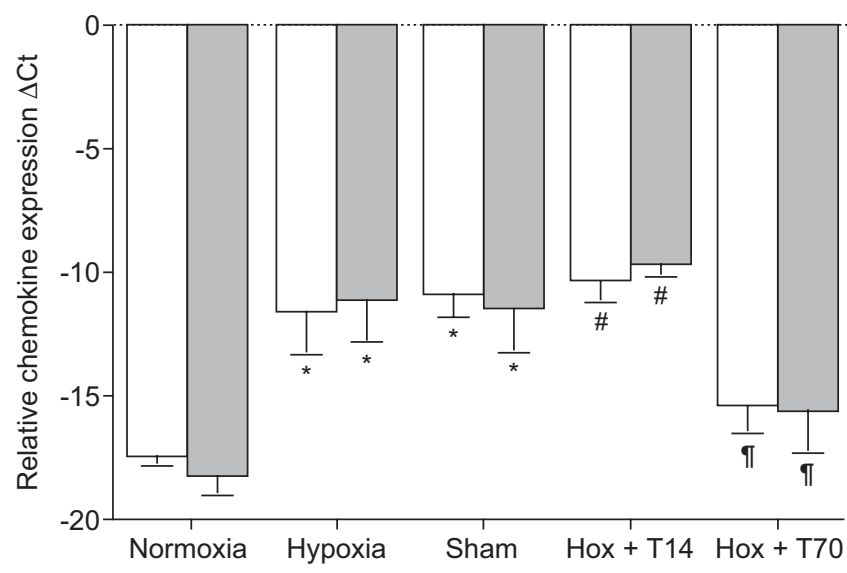

FIGURE 7. Chemokine regulation at mRNA level by quantitative PCR. Upregulation of mRNA of the chemokine receptors CXCR4 ( $\square$ ) and CCR7 ( $\square$ ) in lung tissue of the mice exposed to hypoxic condition (hypoxia and sham animals) compared to normoxic animals. The chemokine expression (CXCR4 and CCR7) did not change with treprostinil treatment at a does of $14 \mathrm{ng} \cdot \mathrm{kg}^{-1} \cdot \mathrm{min}^{-1}(\mathrm{Hox}+\mathrm{T} 14)$ compared to sham animals. However, the treatment at a dose of $70 \mathrm{ng} \cdot \mathrm{kg}^{-1} \cdot \mathrm{min}^{-1}$ $(\mathrm{Hox}+\mathrm{T70})$ significantly downregulated the chemokine expression compared to the sham group. The $18 \mathrm{~S}$ ribosomal RNA was used as an internal control for normalisation to calculate $\triangle \mathrm{Ct}$. Statistical analysis was performed with ANOVA using Bonferroni's post hoc test $(n=5-6) .{ }^{*}: p<0.05$ significant versus normoxia; \#: $p>0.05$ nonsignificant versus sham; ${ }^{\uparrow}: p<0.05$ significant versus sham mice.

vascular remodelling process. Several recent reports have shown the recruitment of circulating fibrocytes in various fibrotic pathological conditions, such as airway remodelling in asthma, parenchymal remodelling in pulmonary fibrosis and vascular remodelling in pulmonary hypertension $[14,15,20,21]$.

In our study, to track the circulating fibrocytes in vivo, we generated GFP bone marrow chimeric mice and subsequently subjected these mice to hypoxia induced pulmonary hypertension. The in vivo characterisation of donor derived circulating fibrocytes (bone marrow-derived GFP positive cells) showed the expression of CD45 along with fibroblast markers collagen I and vimentin. In addition, we showed the presence of circulating fibrocytes (expressing the haematopoietic marker CD45 and the mesenchymal markers collagen1 and vimentin) in the remodelled pulmonary arteries of PAH patients. Our present data provides strong evidence for active recruitment and accumulation of circulating fibrocytes and other bone marrow-derived cells in the pulmonary vessel wall in response to hypoxia. Furthermore, circulating fibrocyte recruitment was significantly inhibited by continuous treprostinil infusion.

Collagen 1+/GFP+ circulating fibrocytes were significantly increased in the vessel walls of pulmonary resistance arteries of chronic hypoxic mice. This cell population is highly likely to contribute to the vascular remodelling process in experimental pulmonary hypertension. Collagen 1-/GFP+ cells represent cells belonging to the immune system, their role in pulmonary vascular remodelling is unresolved but it is a regular observation that inflammatory cells contribute to vascular lesions in experimental and human pulmonary hypertension, possibly by secretion of fibroproliferative mediators $[33,34]$. The data of FRID et al. [20] and BURKE et al. [34] showed strong recruitment of cells of mononuclear origin, predominantly to the adventitial layer in chronic hypoxic calves and rats, with up-regulation of various fibroproliferative markers conductive for vascular remodelling processes.

However, we could not detect bone marrow-derived GFP positive smooth muscle cells in the media of the pulmonary vessels, which is in contrast to a previous report [21], but in line with observations of failure of bone marrow to contribute to pulmonary vascular smooth muscle in monocrotalin induced pulmonary hypertension in rats [35]. The observation of differentiation of bone marrow-derived precursors into $\alpha$-smooth muscle acting expressing myofibroblasts is also varying amongst different groups. PHILLIPS et al. [14] reported myofibroblast generation in experimental lung fibrosis whereas НАSнімОто et al. [19], as well as our group (unpublished data), did not observe this phenomenon in experimental fibrosis. The reason for this is still unclear; variations in the transplant protocols, cell handling or animal strains may be taken into account. Similar failure of bone marrow-derived cells to populate smooth muscle of the lung has been described previously by our group in a model of compensatory lung growth following unilateral pneumonectomy in mice [23].

However, circulating fibrocyte accumulation in the perivascular area in response to chronic hypoxia suggests their contribution to the progression of detrimental vascular remodelling apart from other contributing cell types. Recent data demonstrated that sustained hypoxia creates a pulmonary artery-specific inflammatory microenvironment with upregulation of various growth factors (vascular endothelial growth factor (VEGF), transforming growth factor (TGF)- $\beta$ ), chemokines and cytokines, adhesion molecules as well as monocyte/fibrocyte growth and differentiation markers in rat model of pulmonary hypertension, all of which may promote recruitment, retention and differentiation of circulating cells of mononuclear origin [34].

A study by НАSHIMOTO et al.[19] using a comparable GFP chimeric mouse model, has shown significant contribution $(\sim 27 \%)$ of bone marrow-derived GFP+/collagen $1+$ fibroblasts to bleomycin induced lung fibrosis. In addition, they showed that isolated GFP+ lung fibroblast exhibited CXCR4+/CCR7+ chemokine receptor expression. PHILLIPS et al. [14] addressed the role of circulating fibrocytes by the similar marker profile in pulmonary fibrosis as НАSHIMOTO et al. [19] and positively correlated the recruitment of CD45+/collagen 1+/CXCR4+ circulating fibrocytes to increased collagen deposition in bleomycin induced pulmonary fibrosis. This effect was reversed by treatment with a neutralising antibody against CXCL12, which is the ligand for CXCR4 [14]. Similarly, in another study, CCR2 expression of circulating fibrocytes has been shown to play an important role in fluorescein isothiocyanate induced pulmonary fibrosis [12]. The data from these studies support the fibroproliferative role of circulating fibrocytes and their chemokine receptors.

The increased expression of chemokines, such as stromal derived factor-1, fractalkine, RANTES or monocyte chemotactic protein (MCP)-1, has been demonstrated in $\mathrm{PAH}$ patients as well as in pulmonary hypertension animal models [36-38]. The gene profiling study carried out with laser dissected pulmonary arteries also exhibited the up-regulation of various growth 
factors (vascular growth factor and platelet derived growth factor (PDGF)) and matrix proteins (pro-collagen 1A2 and procollagen1A2) [34, 39]. Human circulating fibrocytes express chemokine receptors of the CC family, namely CCR3, CCR5, CCR7 and the CXC family chemokine CXCR4, whereas mouse fibrocytes express CCR2, CCR7 and CXCR4 along with various growth factors, including MCP-1, TGF- $\alpha$ and TGF- $\beta$, VEGF and PDGF-A [18, 40]. Performing quantitative mRNA expression analysis, we observed a significant increase in the expression of circulating fibrocyte-related chemokine receptors such as CXCR4 and CCR7 in response to hypoxia. The recruitment and consecutive secretion of mediators by this cell population may have profound effects on abnormal proliferation of other cells type such as smooth muscle cells or endothelial cells and thus ascribe to the initiation and/or progression of the remodelling process either via autocrine or paracrine loops. Therefore, circulating fibrocytes may partially mediate effects such as exuberant cell proliferation and extracellular matrix deposition in the pulmonary arterial wall that leads to vascular lumen narrowing and increased vascular resistance. Circulating fibrocytes are shown to promote angiogenesis [41] and thus may be involved in neovascularisation and, possibly, serve as conduit for recruitment of new circulating cells from the circulation at the site of injury [41]. The current data on circulating fibrocyte recruitment in chronic hypoxia encouraged us to further study the cross talk of circulating fibrocytes with other vascular cell types and increased our interest in deciphering the molecular mechanism for the vascular remodelling process.

Prostacyclin $\mathrm{I}_{2}$ and its mimetic have been shown to decrease smooth muscle cell proliferation [42]. Apart from this, prostacyclins inhibit the production of various cytokines and inflammatory mediators and suppress neutrophil adhesion [8, 43]. It has been shown that treprostinil mediates antiproliferative mechanisms of resident lung fibroblasts [44]. Another prostacyclin analogue, iloprost was shown to have a beneficial effect in asthma [45]. The inhaled iloprost suppressed the cardinal feature of asthma in the mouse model by reducing the co-stimulatory molecule expression (CD80/CD86) of the dentritic cells (DCs) in effect affecting pro-inflammatory events. The treatment also altered the cytokine expression and inhibited the migration of the DCs [45]. Circulating fibrocyte also reported to possess the co stimulatory molecules CD80/CD86. Treatment with trperostinil may have similar effect, as mentioned in this study. Thus, our findings of trepostinil induced reduction of circulating fibrocytes in parallel to an overall reduction of pulmonary vascular remodelling may be interpreted as: 1) loss of proliferative signal of circulating fibrocytes on resident fibroblasts and smooth muscle cells; or 2) as direct antiproliferative effects of treprostinil on resident cells in addition to inhibition of CF recruitment. Thus, the true contribution of circulating fibrocytes to pulmonary vascular remodelling can currently not be delivered; a genetic cell targeting approach to decipher this aspect is ongoing.

Treatment of experimental pulmonary hypertension can be carried out terms of "preventive" and "reversing" protocols, i.e. treatment being applied throughout disease development or after onset of significant pulmonary hypertension, respectively. As we assumed that hypoxia leads to recruitment of $\mathrm{CF}$ as part of the pathogenesis, hypoxic mice were treated with treprostinil from the start of hypoxia exposure. This was based on a study on hypoxia-induced pulmonary hypertension in rats which showed recruitment of monocyte/macrophage lineage cells from day 1 until 3-4 weeks of hypoxia exposure [20]. In addition, our in vitro data showed that treprostinil inhibited the adhesion and differentiation of circulating fibrocytes from freshly isolated peripheral blood mononuclear cells but it was ineffective on the completely differentiated circulating fibrocytes with respect to adhesion (unpublished data). Thus we treated the mice with treprostinil from the beginning to evaluate its influence on the circulating fibrocytes to the hypoxic lung during the entire recruitment phase.

The pulmonary haemodynamic changes induced by treprostinil in our experimental pulmonary hypertension model closely resembled the clinical effects of this drug. The continuous infusion of treprostinil in hypoxic mice significantly reduced the pulmonary arterial pressure compared to the hypoxia and sham control group. However, the structural remodelling could not be strongly reversed by treprostinil treatment in the hypoxic chimeric mice with the applied infusion rate of $14 \mathrm{ng} \cdot \mathrm{kg}^{-1} \cdot \mathrm{min}^{-1}$. This rate of infusion has been shown to exert strong effects on human pulmonary haemodynamics and is approximately the starting dose for patients [26-29]. Patients on chronic treprostinil infusion treatment may need increased doses, up to $60 \mathrm{ng} \cdot \mathrm{kg}^{-1} \cdot \mathrm{min}^{-1}$. In an additional set of experiments, we applied a five times higher dose to mice (70 $\mathrm{ng} \cdot \mathrm{kg}^{-1} \cdot \mathrm{min}^{-1}$ ) with the same outcomes on haemodynamics, vascular remodelling and RV hypertrophy. The systemic pressures of minipump implanted mice (either saline filled (sham) or treprostinil filled minipumps (Hox+T14 and Hox+T70) were less compared to nonimplanted mice (normoxia and hypoxia). One explanation could be the surgical intervention and catheterisation of the left jugular vein. Thus whenever the effect of treprostinil had to be assessed, we compared it to sham-infused animals rather than to the hypoxia group animals alone.

We observed significant changes in cell recruitment and haemodynamics but fewer changes in vascular remodelling and ventricular hypertrophy due to treprostinil treatment. The underlying mechanisms for hypoxia induced pulmonary hypertension and smooth muscle cell hyperplasia are not yet clear [46]. Direct proliferative effects of hypoxia on vascular smooth muscle cells may account for the observed hypertrophy. The degree of contribution of circulating fibrocytes to smooth muscle cell hypertrophy and hyperplasia has yet to be defined. Circulating fibrocyte capacity to generate extracellular matrix like collagen 1, fibronectin, however, suggests a role in structural vessel changes. To our knowledge this is first study showing the non-reversal of structural remodelling in a chimeric murine model with treprostinil treatment. A recent investigation exhibited similar findings in advanced monocrotalineinduced pulmonary hypertension in a rat model [47].

The functional connectivity of the parameters hypoxia, pulmonary arterial pressure, right ventricular hypertrophy and pulmonary resistance due to vascular remodelling is not fully understood. Differential effects of various treatments have been observed for hypoxia induced pulmonary hypertension, wherein another prostacyclin analogue (iloprost) was also found to decrease pulmonary arterial pressure without 
reversing the right ventricular hypertrophy and sildenafil was found to prevent right ventricular hypertrophy with modest improvement in pulmonary arterial pressures [21]. It is still unclear if direct effects of hypoxia on myocardial remodelling take place and whether differential impacts of the aforementioned drugs on vasorelaxation, vascular remodelling and myocardial remodelling are operative.

The analysis of lung tissue from idiopathic $\mathrm{PAH}$ patients revealed a low frequency of double positive (CD45+/collagen 1+) fibrocytes in pulmonary resistance arteries. This low frequency of fibrocytes in patient tissue could be assigned to: 1) continuous, long-term intravenous prostacyclin therapy, which all patients received before lung transplantation; 2) the end stage of disease, in which possibly less cell recruitment is ongoing; or 3) a rather quick transition from the haematopoietic marker expressing fibrocyte to mesenchymal markers expressing fibroblast. To resolve the question of cell transition, in vivo cell tracing studies still need to be performed.

In summary, we have shown that bone marrow-derived circulating fibrocytes are recruited to pulmonary resistance arteries in mice upon chronic hypoxic exposure, where they presumably participate in the pathogenesis of pulmonary hypertension development. Circulating fibrocyte recruitment can be selectively inhibited by the stable prostacyclin analogue treprostinil. Further investigations with respect to the origin of these cells, the kinetics of recruitment and cell transition, and the specific effect on vascular remodelling are needed to understand the significance of this cell type in the pathogenesis of pulmonary hypertension.

\section{STATEMENT OF INTEREST}

Statements of interest for R.T. Schermuly, W. Seeger and R. Voswinckel can be found at www.erj.ersjournals.com/site/misc/statements.xhtml

\section{REFERENCES}

1 Ghofrani HA, Voswinckel R, Reichenberger F, et al. Hypoxia- and non-hypoxia-related pulmonary hypertension: established and new therapies. Cardiovasc Res 2006; 72: 30-40.

2 Archer S, Rich S. Primary pulmonary hypertension: a vascular biology and translational research "work in progress". Circulation 2000; 102: 2781-2791.

3 Farber HW, Loscalzo J. Pulmonary arterial hypertension. N Engl J Med 2004; 351: 1655-1665.

4 Stenmark KR, Davie N, Frid M, et al. Role of the adventitia in pulmonary vascular remodeling. Physiology (Bethesda) 2006; 21: 134-145.

5 Stenmark KR, Fagan KA, Frid MG. Hypoxia-induced pulmonary vascular remodeling: cellular and molecular mechanisms. Circ Res 2006; 99: 675-691.

6 Voswinckel R, Enke B, Reichenberger F, et al. Favorable effects of inhaled treprostinil in severe pulmonary hypertension: results from randomized controlled pilot studies. J Am Coll Cardiol 2006; 48: 1672-1681.

7 Gomberg-Maitland M, Olschewski H. Prostacyclin therapies for the treatment of pulmonary arterial hypertension. Eur Respir J 2008; 31: 891-901.

8 Olschewski H, Olschewski A, Rose F, et al. Physiologic basis for the treatment of pulmonary hypertension. J Lab Clin Med 2001; 138: 287-297.

9 Asahara T, Masuda H, Takahashi $\mathrm{T}$, et al. Bone marrow origin of endothelial progenitor cells responsible for postnatal vasculogenesis in physiological and pathological neovascularization. Circ Res 1999; 85: $221-228$

10 Shi $\mathrm{Q}$, Rafii $\mathrm{S}, \mathrm{Wu} \mathrm{MH}$, et al. Evidence for circulating bone marrow-derived endothelial cells. Blood 1998; 92: 362-367.

11 Krause DS, Theise ND, Collector MI, et al. Multi-organ, multilineage engraftment by a single bone marrow-derived stem cell. Cell 2001; 105: 369-377.

12 Moore BB, Kolodsick JE, Thannickal VJ, et al. CCR2-mediated recruitment of fibrocytes to the alveolar space after fibrotic injury. Am J Pathol 2005; 166: 675-684.

13 Moore BB, Murray L, Das A, et al. The role of CCL12 in the recruitment of fibrocytes and lung fibrosis. Am J Respir Cell Mol Biol 2006; 35: 175-181.

14 Phillips RJ, Burdick MD, Hong K, et al. Circulating fibrocytes traffic to the lungs in response to CXCL12 and mediate fibrosis. J Clin Invest 2004; 114: 438-446.

15 Schmidt M, Sun G, Stacey MA, et al. Identification of circulating fibrocytes as precursors of bronchial myofibroblasts in asthma. J Immunol 2003; 171: 380-389.

16 Aiba S, Tabata N, Ohtani H, et al. CD34+ spindle-shaped cells selectively disappear from the skin lesion of scleroderma. Arch Dermatol 1994; 130: 593-597.

17 Cowper SE, Bucala R. Nephrogenic fibrosing dermopathy: suspect identified, motive unclear. Am J Dermatopathol 2003; 25: 358.

18 Bucala R, Spiegel LA, Chesney J, et al. Circulating fibrocytes define a new leukocyte subpopulation that mediates tissue repair. Mol Med 1994; 1: 71-81.

19 Hashimoto $\mathrm{N}$, Jin $\mathrm{H}$, Liu T, et al. Bone marrow-derived progenitor cells in pulmonary fibrosis. J Clin Invest 2004; 113: 243-252.

20 Frid MG, Brunetti JA, Burke DL, et al. Hypoxia-induced pulmonary vascular remodeling requires recruitment of circulating mesenchymal precursors of a monocyte/macrophage lineage. Am J Pathol 2006; 168: 659-669.

21 Hayashida K, Fujita J, Miyake Y, et al. Bone marrow-derived cells contribute to pulmonary vascular remodeling in hypoxia-induced pulmonary hypertension. Chest 2005; 127: 1793-1798.

22 Okabe M, Ikawa M, Kominami K, et al. "Green mice" as a source of ubiquitous green cells. FEBS Lett 1997; 407: 313-319.

23 Voswinckel R, Ziegelhoeffer $\mathrm{T}$, Heil $\mathrm{M}$, et al. Circulating vascular progenitor cells do not contribute to compensatory lung growth Circ Res 2003; 93: 372-379.

24 Weissmann N, Gerigk B, Kocer O, et al. Hypoxia-induced pulmonary hypertension: different impact of iloprost, sildenafil, and nitric oxide. Respir Med 2007; 101: 2125-2132.

25 Schermuly RT, Dony E, Ghofrani HA, et al. Reversal of experimental pulmonary hypertension by PDGF inhibition. J Clin Invest 2005; 115: 2811-2821.

26 Laliberte K, Arneson C, Jeffs R, et al. Pharmacokinetics and steady-state bioequivalence of treprostinil sodium (remodulin(r)) administered by the intravenous and subcutaneous route to normal volunteers. J Cardiovasc Pharmacol 2004; 44: 209-214.

27 McSwain CS, Benza R, Shapiro S, et al. Dose proportionality of treprostinil sodium administered by continuous subcutaneous and intravenous infusion. J Clin Pharmacol 2008; 48: 19-25.

28 Wade M, Baker FJ, Roscigno R, et al. Pharmacokinetics of treprostinil sodium administered by 28-day chronic continuous subcutaneous infusion. J Clin Pharmacol 2004; 44: 503-509.

29 Wade M, Baker FJ, Roscigno R, et al. Absolute bioavailability and pharmacokinetics of treprostinil sodium administered by acute subcutaneous infusion. J Clin Pharmacol 2004; 44: 83-88.

30 Hopkins N, Cadogan E, Giles S, et al. Chronic airway infection leads to angiogenesis in the pulmonary circulation. J Appl Physiol 2001; 91: 919-928.

31 Abe R, Donnelly SC, Peng T, et al. Peripheral blood fibrocytes: differentiation pathway and migration to wound sites. J Immunol 2001; 166: 7556-7562. 
32 Sakai N, Wada T, Yokoyama H, et al. Secondary lymphoid tissue chemokine (SLC/CCL21)/CCR7 signaling regulates fibrocytes in renal fibrosis. Proc Natl Acad Sci USA 2006; 103: 14098-14103.

33 Tuder RM, Groves B, Badesch DB, et al. Exuberant endothelial cell growth and elements of inflammation are present in plexiform lesions of pulmonary hypertension. Am J Pathol 1994; 144: 275-285.

34 Burke DL, Frid MG, Kunrath CL, et al. Sustained hypoxia promotes the development of a pulmonary artery-specific chronic inflammatory microenvironment. Am J Physiol Lung Cell Mol Physiol 2009; 297: L238-L250.

35 Sahara M, Sata M, Morita T, et al. Diverse contribution of bone marrow-derived cells to vascular remodeling associated with pulmonary arterial hypertension and arterial neointimal formation. Circulation 2007; 115: 509-517.

36 Balabanian K, Foussat A, Dorfmuller P, et al. CX(3)C chemokine fractalkine in pulmonary arterial hypertension. Am J Respir Crit Care Med 2002; 165: 1419-1425.

37 Dorfmuller P, Zarka V, Durand-Gasselin I, et al. Chemokine RANTES in severe pulmonary arterial hypertension. Am J Respir Crit Care Med 2002; 165: 534-539.

38 Ikeda Y, Yonemitsu Y, Kataoka C, et al. Anti-monocyte chemoattractant protein-1 gene therapy attenuates pulmonary hypertension in rats. Am J Physiol Heart Circ Physiol 2002; 283: H2021-H2028.

39 Kwapiszewska G, Wilhelm J, Wolff S, et al. Expression profiling of laser-microdissected intrapulmonary arteries in hypoxia-induced pulmonary hypertension. Respir Res 2005; 6: 109.
40 Quan TE, Cowper S, Wu SP, et al. Circulating fibrocytes: collagensecreting cells of the peripheral blood. Int J Biochem Cell Biol 2004; 36: 598-606.

41 Hartlapp I, Abe R, Saeed RW, et al. Fibrocytes induce an angiogenic phenotype in cultured endothelial cells and promote angiogenesis in vivo. FASEB J 2001; 15: 2215-2224.

42 Clapp LH, Finney P, Turcato S, et al. Differential effects of stable prostacyclin analogs on smooth muscle proliferation and cyclic AMP generation in human pulmonary artery. Am J Respir Cell Mol Biol 2002; 26: 194-201.

43 Raychaudhuri B, Malur A, Bonfield TL, et al. The prostacyclin analogue treprostinil blocks $\mathrm{NF} \kappa \mathrm{B}$ nuclear translocation in human alveolar macrophages. J Biol Chem 2002; 277: 33344-33348.

44 Ali FY, Egan K, FitzGerald GA, et al. Role of prostacyclin versus peroxisome proliferator-activated receptor beta receptors in prostacyclin sensing by lung fibroblasts. Am J Respir Cell Mol Biol 2006; 34: 242-246.

45 Idzko M, Hammad H, van Nimwegen M, et al. Inhaled iloprost suppresses the cardinal features of asthma via inhibition of airway dendritic cell function. J Clin Invest 2007; 117: 464-472.

46 Weissmann N. Hypoxia-driven mechanisms in lung biology and disease: a new review series of the ERS Lung Science Conference. Eur Respir J 2008; 31: 697-698.

47 van Albada ME, van Veghel R, Cromme-Dijkhuis $\mathrm{AH}$, et al. Treprostinil in advanced experimental pulmonary hypertension: beneficial outcome without reversed pulmonary vascular remodeling. J Cardiovasc Pharmacol 2006; 48: 249-254. 